\title{
Assessment of Climate Change Variability Impacts on Wheat and Barley Production in Palestine
}

\author{
Imadeddin Albaba \\ Freelancer and independent researcher, Halhul 741, West Bank, Palestine
}

\begin{abstract}
The study aimed at addressing climate variability impacts on wheat and barley production in Palestine. A combination of literature survey and multiple semi-structured interviews with officials from the Palestinian governmental agriculture related agencies and active non-governmental organizations (NGOs) used for gathering information on wheat and barley production in Palestine. The gathered data along with information and subsequent results prevailed that the West Bank since the 1970s has experienced a significant decrease in winter rainfall. Across 15 sites, growing season rainfall (September to May) decreased by an average of $11 \%$ and the sum of rainfall in September and October decreased by $45 \%$. Despite the large decline in rainfall, yields based on the actual weather data did not fall. These results were due to the rainfall changes mainly occurring in September and October, a period when rainfall often is less than crop demand. The study arrived at conclusion based on the study results that climate change variabilities have differential impacts on the yield growth of wheat and barley. However, both rainfed dependent crops are adversely affected by the current climate trends. The yields of barley and wheat are decreasing due to increased temperature and decreased precipitation.
\end{abstract}

Key words: Climate change, barely, wheat, Palestine.

\section{Introduction}

Climate change has been a major issue challenging the agricultural sector in Palestine, and directly affecting agricultural production, mainly due to changes and fluctuations in rainfall quantities, and the disintegration of agricultural holdings reducing their productivity, efficiency and profitability [1].

The latest agricultural census published by the Ministry of Agriculture and the Palestinian Central Bureau of Statistics (PCBS) in 2010 estimated that the total area of agricultural land was 1,207,061 dunum (one dunum is the equivalent of 0.1 ha; $91.6 \%$ or 1,694,554 dunum in the West Bank and $8.4 \%$ in the Gaza Strip) [2].

The PCBS reports estimated that the value of Palestinian agricultural production was \$1,295 million (70\% in the West Bank and 30\% in the Gaza Strip) [3]. But, the agricultural sector's contribution to the

Corresponding author: Imadeddin Albaba, M.Sc., research fields: natural resources management and their sustainability.
Palestinian gross domestic product (GDP) was only 4.1\% in the year 2013 and 3.4\% of the GDP of the West Bank [4]. Accordingly, the agricultural sector's contribution to GDP has been declining over the years, due to growth in other sectors.

The analysis of the agricultural sector and its activities shows that the sector is facing many challenges and obstacles. The political conflict in Palestine is the most critical. The climate change has also been a major issue challenging the agricultural sector in Palestine, and directly affecting agricultural production, mainly due to changes and fluctuations in rainfall quantities, and the disintegration of agricultural holdings reducing their productivity, efficiency and profitability.

In Palestine, about 143,326 dunum of agricultural land has been utilized for the cultivation of wheat (Triticum aestivum L.) in the West Bank in the year $2012 / 2013$. Wheat cropping is mainly practiced in areas with an average annual rainfall ranging between $280 \mathrm{~mm} /$ year and $550 \mathrm{~mm} /$ year. The planted areas 
show a distinct Mediterranean climate with cool, wet winters and hot, dry summers. Over $75 \%$ of the rain falls between October and March [5]. The main producer governorates are as follow: Jenin Governorate is the highest producer of wheat, constituting $54 \%$ of total production, followed by Hebron Governorate (16\%) and Nablus Governorate (11\%) [1].

In Palestine, about 8,568 dunum of agricultural land has been utilized for the cultivation of barley (Hordeum vulgare L.) in the West Bank in the year 2013/2014. Barley cropping is mainly practiced in areas with an average annual rainfall ranging between $250 \mathrm{~mm} /$ year and $500 \mathrm{~mm} /$ year. The planted areas show a distinct Mediterranean climate with cool, wet winters and hot, dry summers. Over $75 \%$ of the rain falls between October and March [5]. The main producer governorates are as follow: Jenin Governorate is the highest producer of barley constituting $46 \%$ of total production, followed by Hebron Governorate (21\%) and Nablus Governorate (16\%) [5]. The study aimed at addressing climate change variability impacts on wheat and barley production in Palestine.

\section{Materials and Methods}

\subsection{Study Area}

The West Bank covers an area of about 5,655 km². The area is located within the following geographical coordinates $31.9466^{\circ} \mathrm{N}, 35.3027^{\circ} \mathrm{E}$.

\subsection{Survey}

A combination of literature survey and multiple interviews with officials from the Palestinian governmental agriculture related agencies and active non-governmental organizations (NGOs) was used for gathering information on wheat and barley production in Palestine. Semi-structured interviews were designed. The survey selected 18 informants distributed among the Palestinian officials, NGOs of the West Bank governorates during a period between
March and May, 2017. At least two key informants were interviewed regarding each of the main topics of wheat and barley production of Palestine.

The precipitation and temperature datasets were obtained from the Palestinian Meteorological Department, which is part of the Ministry of Transport. The wheat and barley production datasets were obtained from the Ministry of Agriculture, as well as from the PCBS. Additional information concerning with wheat and barley production, annual rainfall and temperature was obtained from the interviewed informants of the Palestinian relevant government and NGOs in the West Bank governorates. The statistical analysis was done using SigmaStat 3.5 software.

\section{Results and Discussion}

\subsection{Climate Change}

According to the interview respondents, both summer and winter seasons are warmer at present years 2007-2017, not as 20 years ago. In addition, the annual precipitations were reduced and fluctuated for the years 2007-2017, not as 20-30 years ago. In addition, the precipitation pattern has changed, and they are experiencing untimely, either heavy rainfall or winter drought, and other phenomena more frequently than before.

The statistical analysis of the obtained data from the Palestinian Meteorological Department in Table 1 prevailed high standard deviation in the datasets of annual rainfall, temperature and evaporation rates. A high standard deviation suggests that year-to-year fluctuations of the analyzed variables, rainfall, temperature and evaporation are high.

The positive kurtosis indicates a distinct peak near the mean, declining rather rapidly like the temperature variable in the data while the negative kurtosis indicates a flat top near the mean rather than a sharp peak distribution. Hence, the annual rainfall and evaporation rates distribution under consideration did not follow normal distribution. 
The skewness is a measure of the lack of symmetry of variables datasets. Negative values for the skewness indicate that data are skewed to the left like the case of the rainfall in this study while positive values for the skewness indicate that data are skewed to the right like the cases of temperature and evaporation rates in this study as shown in Table 1.

The high value of variance in Table 1 indicates the existence of strong variability in the rainfall and evaporating rates. The analysis of temperature and rainfall changes in the last 36 years (1980-2016) in the studied area showed that over time, the annual mean temperature has been increased, and the annual mean of rainfall decreased. In a way that about $0.046{ }^{\circ} \mathrm{C}$ being added to the mean temperature of the West Bank increased about $0.046{ }^{\circ} \mathrm{C}$ annually, and the annual mean of rainfall decreased about $11 \%$. These results confirm the climate change phenomena for this part of the world.

The logarithmic data sets trend analysis for three variables (rainfall, temperature and evaporation) over the years 1985-2016, indicates a decrease in the annual rainfall, as shown in Fig. 1, and an increase in the annual temperature as shown in Fig. 2, and finally an increase in the evaporation rates as shown in Fig. 3.

Table 1 Descriptive statistics of annual rainfall, temperature and evaporation.

\begin{tabular}{llll}
\hline & Annual rainfall $(\mathrm{mm})$ & Annual temperature $\left({ }^{\circ} \mathrm{C}\right)$ & Annual evaporation $(\mathrm{mm})$ \\
\hline Mean & 488.41 & 16.88 & $1,622.45$ \\
Standard deviation & 116.76 & 1.92 & 322.59 \\
Kurtosis & -0.45 & 0.41 & -0.79 \\
Skewness & -0.02 & 0.28 & 0.27 \\
Variance & $13,631.94$ & 3.70 & $104,064.19$ \\
\hline
\end{tabular}

Data source: Palestinian Meteorological Department.

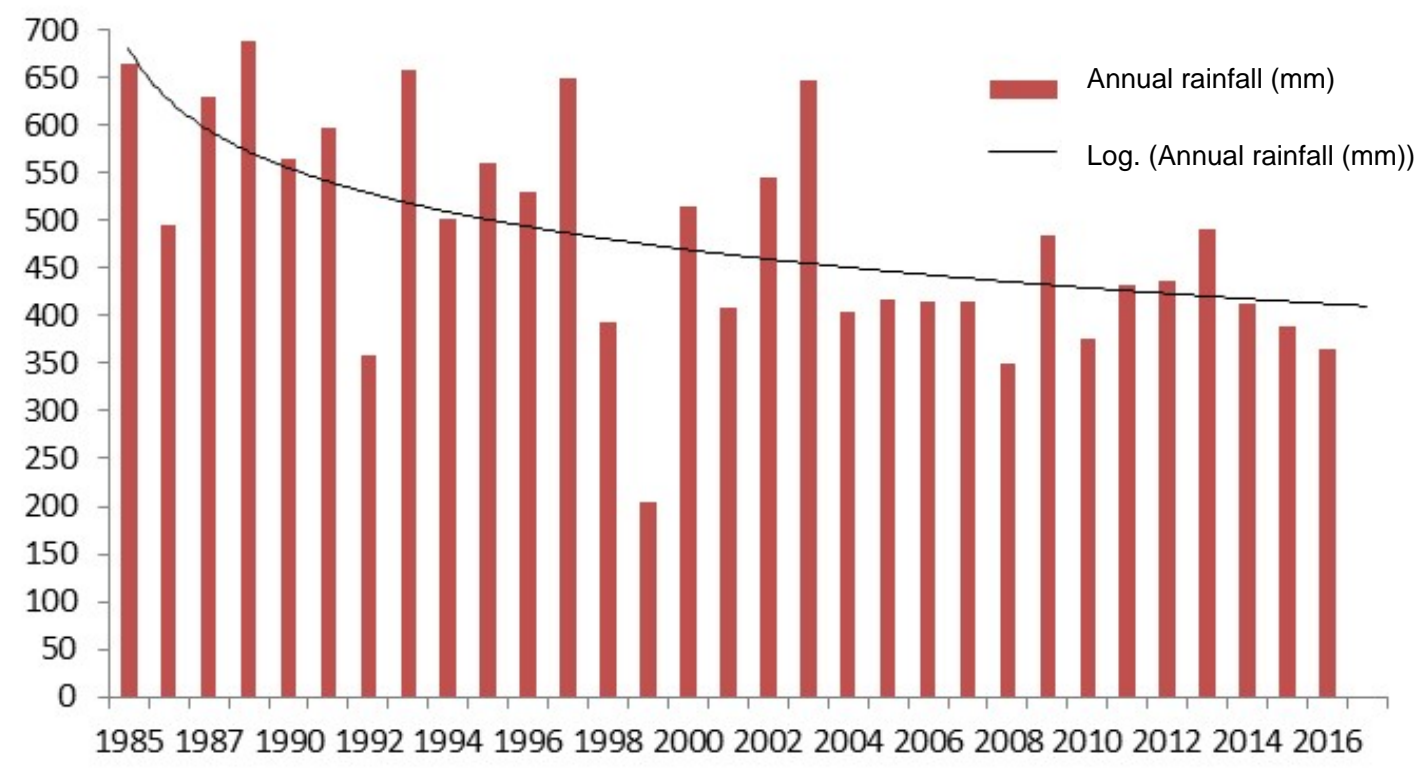

Fig. 1 The annual rainfall logarithmic trend in the West Bank governorates, Palestine in 1985-2016. 


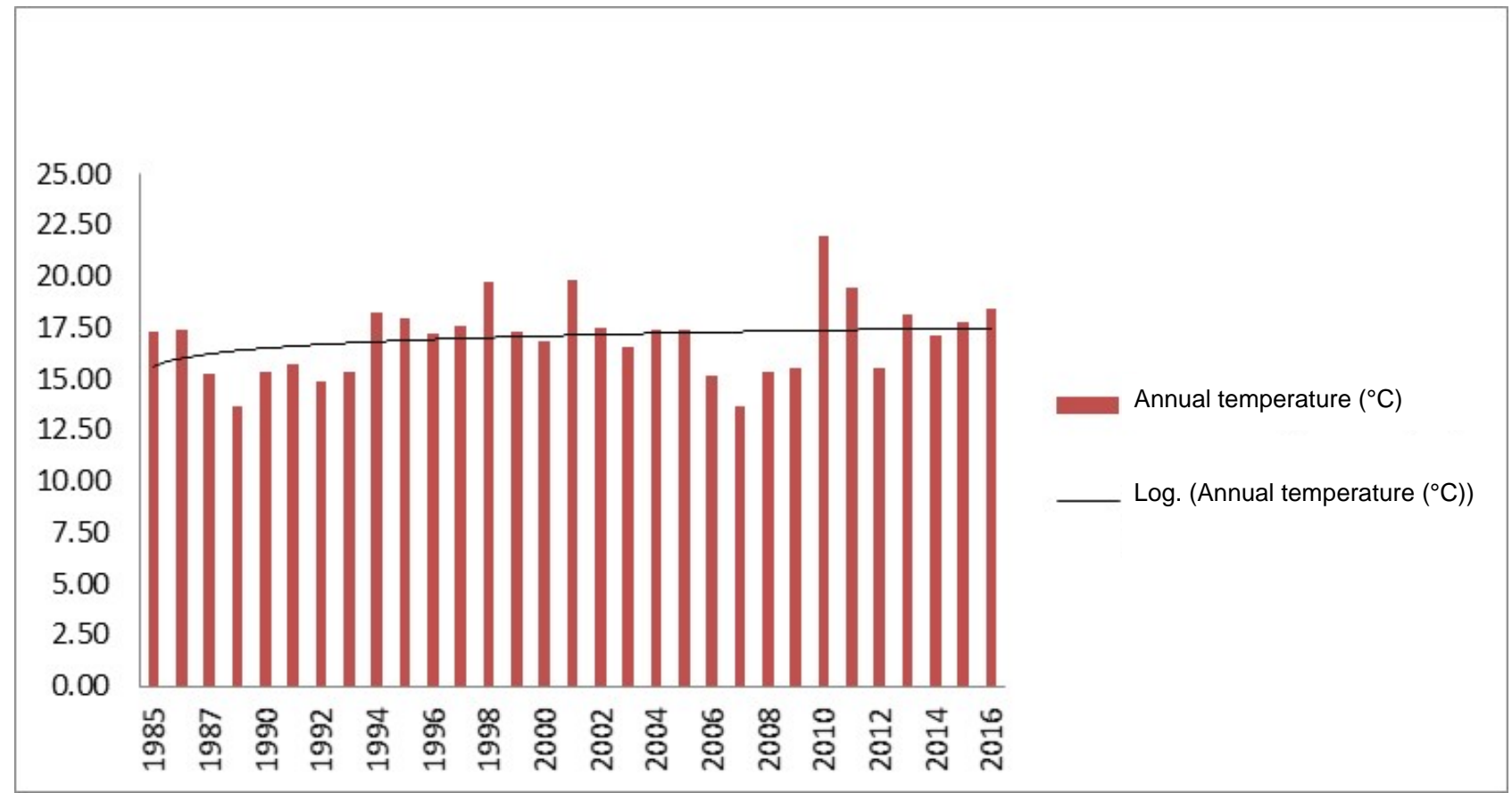

Fig. 2 The annual temperature logarithmic trend in the West Bank governorates, Palestine in 1985-2016.

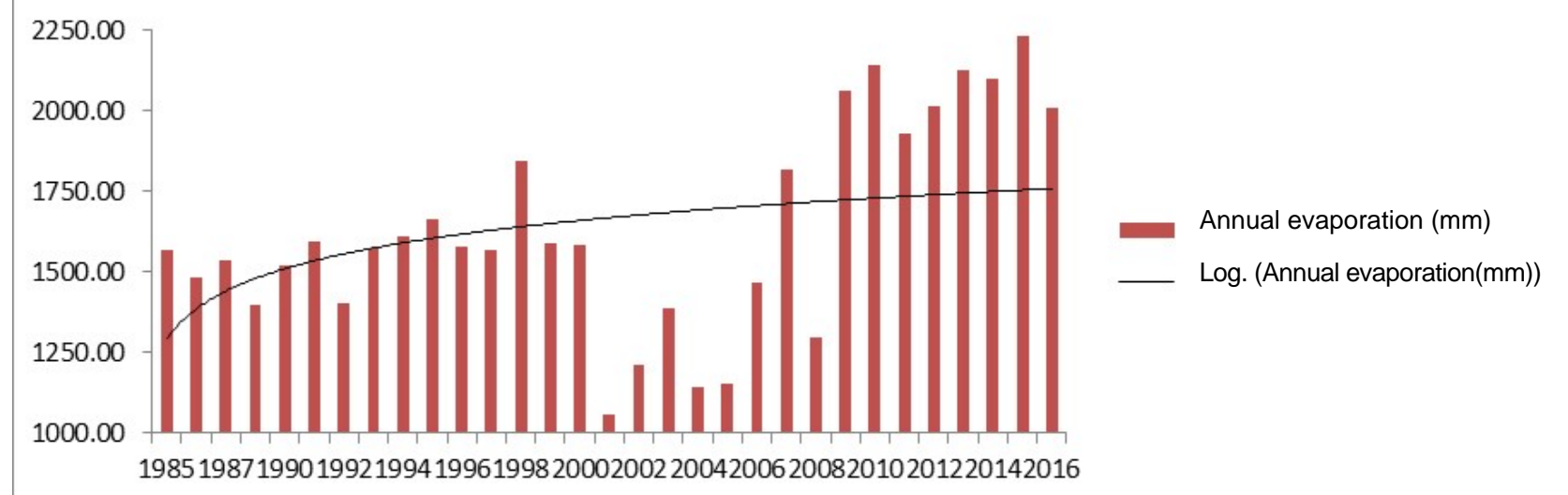

Fig. 3 The annual evaporation (mm) logarithmic trend in the West Bank governorates, Palestine in 1985-2016.

\subsection{Climate Change Impact on Wheat Production in} Palestine

3.2.1 The Growing Period (The Number of the Days from Planting to Flowering)

The growing period of wheat in the West Bank governorates was less in almost $12 \%$ than the normal situation (230-240 d), and thus reduces the wheat growth season. Though it has been reported that in the areas where the crop's growth season encounters limitation, climate change and earth warming can lead to the improvement of crops' yield by increasing the growth season period and the improvement of the plant flowering strength [5]. The rise in temperature will increase the growth and development speed of the crops, though experimental evidence has shown that under this condition, the length of maturity of the seed in the grains and seedy plants will be reduced [6]. Another study by Menzel [7], in the year 2003, stated that the rise in temperature leads to the shorter length 
period of grain filling in the grains and thus will decrease the quality of these products, since achieving optimal quality depends on the solid material accumulation during the growth season on one hand and also on the existence of enough time to transfer the material to the grain on the other hand.

Wheat grain crop growth in Palestine normally peaks from the middle of May to late of June, when wheat crops reach the flowering growth stage. However in the last 10-15 years, the shortages of rainfall slowed crop development, resulting in peak development occurring 6-7 weeks earlier as shown in Table 2.

\subsubsection{The Wheat Production Quantity}

The data analysis results of wheat yield showed that a decrease will occur under the influence of future climate changes in the West Bank governorates. The reduction rate of wheat yield was variable between $1.37 \%$ and $71.51 \%$ for the years $2004-2015$. Mitchell et al. [8] observed that the plant yield showed reduction between $16 \%$ and $35 \%$ under the impact of temperature rise. Saarikko and Carter [9] in the year 1996 also stated that the wheat yield was reduced in southern areas of Finland, as a result of global warming impact on the wheat production. Change in temperature and rainfall level affects the plant photosynthesis, growth, absorption rate of water and nutrient distribution and subsequently affects the leaf area index [9].

\subsubsection{Wheat Yield Trend}

The yield trend of wheat crop showed that the yield has changed significantly over time $(p<0.05)$. However, the yield has fluctuated over time. Wheat had the highest regression coefficient versus time. The yield of wheat decreased by $176.31 \mathrm{~kg} /$ dunum in the year 2000 and $4.74 \mathrm{~kg} /$ dunum in the year 2005, and continued to decrease in other years.

The statistical analysis of the study results showed high value of standard deviations which reflect more uncertainty of the data obtained from official governmental and NGOs resources, as shown in Fig. 4 and Table 3.

\subsection{Climate Change Impact on Barley Production Quantity in Palestine}

3.3.1 The Growing Period (The Number of the Days from Planting to Flowering)

In the West Bank governorates, the winter grain-growing season lasts from late September to May, with some late harvesting occurring in June. The most important yield determination phases, however, occur from March to May. Spring weather conditions therefore have the most significant impacts on crop production potential and grain quality. The growing period of barley in all observed sites was less in almost 19\% than the normal situation (210-220 d), and thus reduces the barley growth season. The rise in temperature increased the growth and development speed of the crops, though experimental evidence has showed that under this condition, the length of maturity of the seed in the grains and seedy plants will be reduced. Other authors also reported in the studies of climate change, and stated that the rise in temperature leads to the shorter length period of grain filling in the grains and thus will decrease the quality of these products, since achieving optimal quality depends on the solid material accumulation during the

Table 2 Mean growing period of wheat in years.

\begin{tabular}{llll}
\hline Years & Mean growing period of wheat in year (d) & Difference (\%) & Difference in number of days \\
\hline 1980 & 226 & 0.04 & 9 \\
1985 & 213 & 0.09 & 22 \\
1990 & 217 & 0.08 & 18 \\
2000 & 210 & 0.11 & 25 \\
2005 & 192 & 0.18 & 43 \\
2010 & 195 & 0.17 & 40 \\
2015 & 197 & 0.16 & 38 \\
\hline
\end{tabular}

Data source: Palestinian Ministry of Agriculture. 


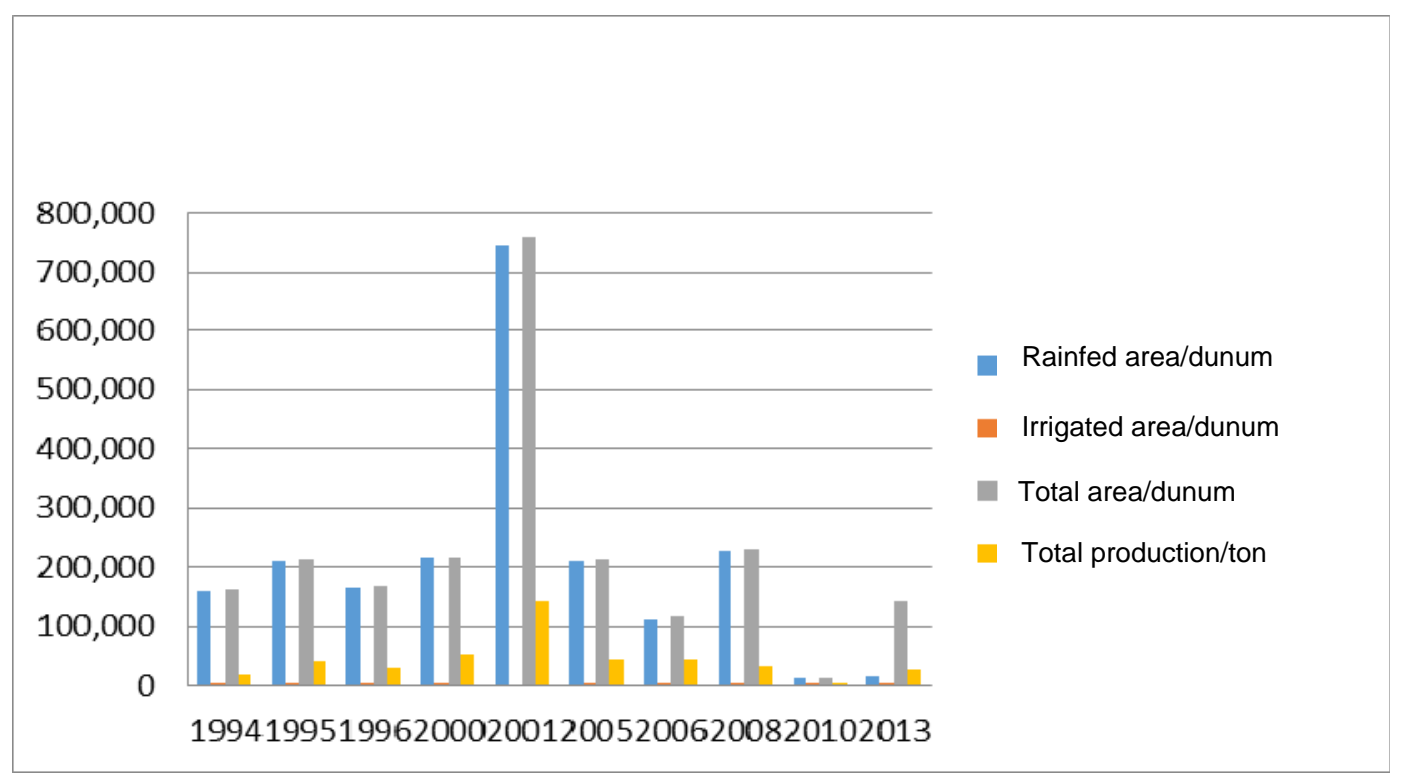

Fig. 4 Wheat production types and area in Palestine in 1994-2013.

Data source: Palestinian Ministry of Agriculture.

Table 3 Descriptive statistics for wheat in 1994-2013.

\begin{tabular}{lllll}
\hline Variables & Mean & Standard deviation & Min. & Max. \\
\hline Cropping area (dunum) & $203,396.5$ & $287,206.91$ & 13,877 & $1,203,947$ \\
Production (ton) & $39,515.25$ & $69,827.83$ & $1,841.21$ & 245,392 \\
Max. temperature $\left({ }^{\circ} \mathrm{C}\right)$ & 10.85 & 3.11 & 10.37 & 21.7 \\
Min. temperature $\left({ }^{\circ} \mathrm{C}\right)$ & 8.40 & 17.58 & 0.00 & 14.6 \\
Rainfall (mm/year) & 393.25 & 436.50 & 180 & 713.8 \\
\hline
\end{tabular}

Table 4 Mean growing period of barley in years.

\begin{tabular}{llll}
\hline Years & Mean growing period of barley in year $(\mathrm{d})$ & Difference $(\%)$ & Difference in number of days \\
\hline 1980 & 225 & -0.02 & -5 \\
1985 & 203 & -0.10 & -22 \\
1990 & 211 & 0.04 & 8 \\
2000 & 182 & -0.13 & -29 \\
2005 & 178 & -0.02 & -4 \\
2010 & 190 & 0.05 & 12 \\
2015 & 177 & -0.06 & -13 \\
\hline
\end{tabular}

Data source: Palestinian Ministry of Agriculture.

growth season on one hand and also on the existence of enough time to transfer the material to the grain on the other hand $[6,7,10-12]$.

Barley grain crop growth in Palestine normally peaks in late April to middle of June, when barley crops reach the flowering growth stage. However, in the last 10 years, the shortages of rainfall slowed crop development, resulting in peak development occurring 4-5 weeks earlier as shown in Table 4.

\subsubsection{The Barley Production Quantity}

The results indicated a very large decrease in crop area $(-67 \%$ and $-62 \%$ for barley, relative to the average of 1994 and 2014) as shown in Fig. 5. A number of existing yield studies on barley also confirm such finding, like available evidence shows that the decrease in the grain filling period due to the rise in temperature is the main factor in the yield decrease of the crops in the climate change condition $[12,13]$. 


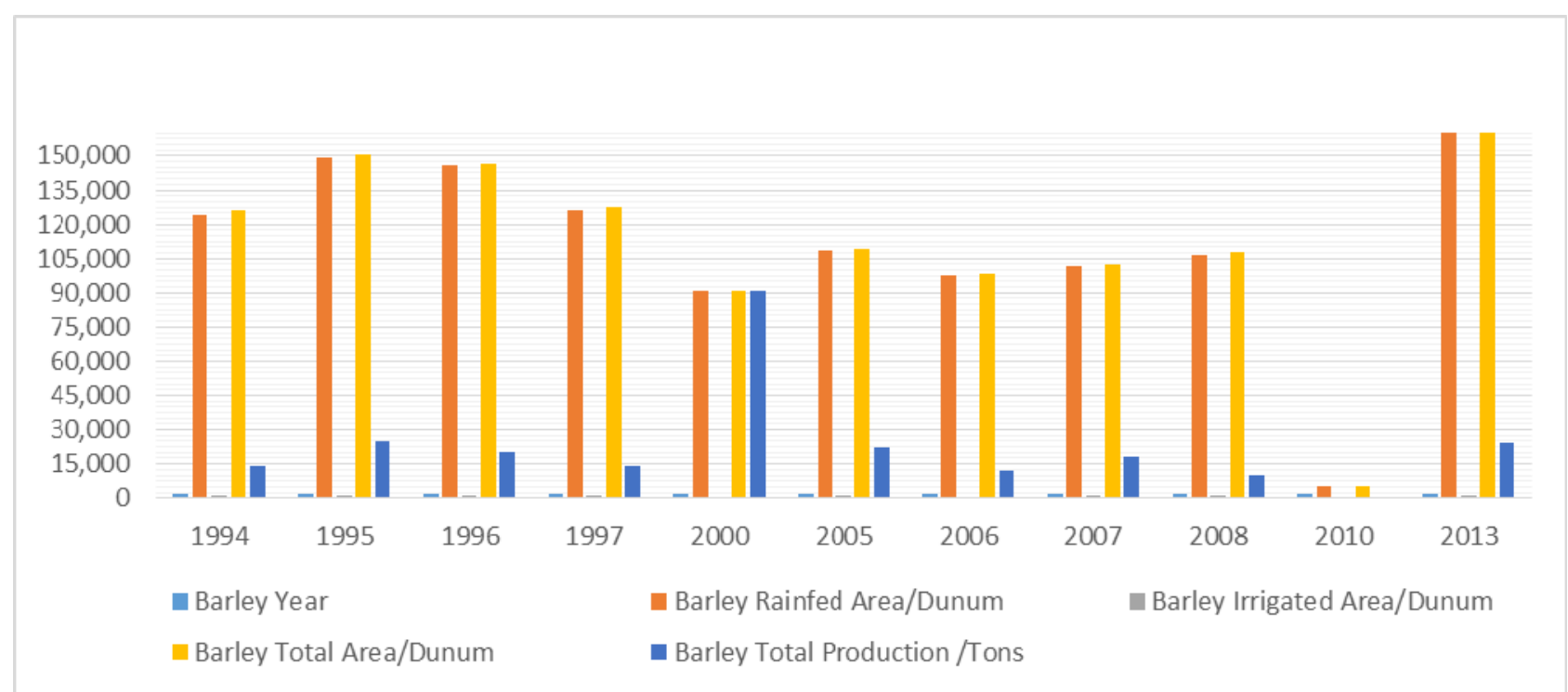

Fig. 5 Barley production types and area in Palestine in 1994-2013.

Table 5 Descriptive statistics for barley in 1994-2013.

\begin{tabular}{lllll}
\hline Variables & Mean & Standard deviation & Min. & Max. \\
\hline Cropping area (dunum) & 112,263 & 473.84 & 5,104 & 170,651 \\
Production (ton) & $22,871.768$ & $42,704.20$ & 648.8 & 90,834 \\
Max. temperature $\left({ }^{\circ} \mathrm{C}\right)$ & 10.85 & 3.11 & 10.37 & 21.7 \\
Min. temperature $\left({ }^{\circ} \mathrm{C}\right)$ & 8.40 & 17.58 & 0.00 & 14.6 \\
Rainfall (mm/year) & 393.25 & 436.50 & 180 & 713.8 \\
\hline
\end{tabular}

\subsubsection{Barley Yield Trend}

Barley decreased by $4.74 \mathrm{~kg} /$ dunum every year. But these changes were not significant $(p>0.05)$ with respect to the time variable as shown in Table 5.

The study results revealed that there was a strong and positive relationship between the climatic variability and the yield of wheat and barley cropping in Palestine.

Climate change is likely to change the precipitation and temperature patterns in ways that could affect the current agricultural production of Palestine. The decreasing trend in precipitation and the increasing trend in temperature could have a negative impact on crops due to water-induced disasters, such as floods and droughts, which eventually affect the crop yields. For the two crops studied here, the growth yield of barley was suppressed by the increased minimum and maximum temperatures and decreased precipitation.

\section{Conclusions}

The study results show that climate change variables have differential impacts on the yield growth of wheat and barley. However, both rainfed dependant crops are adversely affected by the current climate trends. The yields of barley and wheat are decreasing due to increased temperatures and decreased precipitation. Thus, it is recommended that any programs that are working to minimize the adverse impact of climate change on wheat and barley production should first consider these crops, which are being most affected by the higher temperatures and are also exposed to higher degrees of vulnerability to climate change. Therefore, further studies/surveys are highly recommended for better understanding of the patterns and consequences of climate change affecting wheat and barley production in Palestine. 


\section{References}

[1] The Applied Research Institute-Jerusalem (ARIJ). 2015. Palestinian Agricultural Production and Marketing between Reality and Challenges. Executive Summary for a Research Study, 6-10.

[2] Palestinian Central Bureau of Statistics (PCBS). 2012. Agricultural Census-2010. Available: http://www.pcbs.gov.ps/pcbs_2012/Publications.aspx.

[3] Palestinian Central Bureau of Statistics (PCBS). 2012. National Accounts Report. http://www.pcbs.gov.ps/pcbs_2012/Publications.aspx.

[4] Palestinian Ministry of Agriculture. 2013. "Cultivated Area of Surveyed Crops 2012/2013.” Unpublished Data.

[5] Challinor, A. J., Wheeler, T. R., Craufurd, P. Q., Ferro, C. A. T., and Stephenson, D. B. 2007. "Adaptation of Crops to Climate Change through Genotypic Responses to Mean and Extreme Temperatures Agriculture.” Ecosystems and Environment 119 (1-2): 190-204.

[6] Parry, M., Rosenzweig, C., Inglesias, A., Livermore, M., and Gischer, G. 2004. "Effects of Climate Change on Global Food Production under SRES Emissions and Socio-Economic Scenarios.” Global Environment Change 14 (1): 53-67.

[7] Menzel, A. 2003. "Plant Phenological Anomalies in Germany and Their Relation to Air Temperature and NAO.” Climate Change 57 (3): 243-63.

[8] Mitchell, R. A. C., Lawlor, D. W., Mitchell, V. J., Gibbard, C. L., White, E. M., and Porter, J. R. 1995.
"Effects of Elevated $\mathrm{CO}_{2}$ Concentration and Increased Temperature on Winter Wheat: Test of ARCWHEAT1 Simulation Model.” Plant Cell Environment 18 (7): 736-48.

[9] Saarikko, R. A., and Carter, T. R. 1996. "Estimating the Development and Regional Thermal Suitability of Spring Wheat in Finland under Climatic Warming." Climatic Research 7 (3): 243-52.

[10] Holdena, N. M., Breretona, A. J., Fealyb, R., and Sweeneyb, J. 2003. "Possible Change in Irish Climate and Its Impact on Barley and Potato Yields.” Agricultural and Forest Meteorology 116 (3-4): 181-96.

[11] Matthew, G., Pierre, M., and Ariel, O. B. 2016. “The Impact of Climate Change on Cereal Yields: Statistical Evidence from France.” Presented at Agricultural \& Applied Economics Association's AAEA Annual Meeting, Boston, MA, USA.

[12] Asseng, S., Ewert, F., Martre, P., Rötter, R. P., Lobell, D. B., Cammarano, D., et al. 2015. "Rising Temperatures Reduce Global Barley Production.” Nature Climate Change 5 (2): 143-7.

[13] Teresa, T., Salvatore, L. B., Giusep, P. L., and Claudio, L. 2008. "Simulation of the Effects of Climate Change on Barley Yields in Rural Italy.” Available: http://www.fao.org/fileadmin/templates/ess/pages/rural/w ye_city_group/2009/Paper_5_2_Lecardane_Simulation_o f_the_effects_of_climate_change_on_barley_yields_in_r ural_Italy.pdf. 
Appendix

Table 1 The annual rainfall, temperature and evaporation rates in the West Bank governorates, Palestine in the years 1984-2016.

\begin{tabular}{|c|c|c|c|c|}
\hline & Year & Annual rainfall (mm) & Annual temperature $\left({ }^{\circ} \mathrm{C}\right)$ & Annual evaporation $(\mathrm{mm})$ \\
\hline 1 & 1973-1984 & 621.46 & 13.24 & $1,250.52$ \\
\hline 2 & 1985 & 665.60 & 17.35 & $1,566.29$ \\
\hline 3 & 1986 & 495.80 & 17.43 & $1,483.23$ \\
\hline 4 & 1987 & 631.00 & 15.22 & $1,534.12$ \\
\hline 5 & 1988 & 689.30 & 13.69 & $1,398.74$ \\
\hline 6 & 1990 & 565.60 & 15.38 & $1,522.33$ \\
\hline 7 & 1991 & 598.10 & 15.75 & $1,596.75$ \\
\hline 8 & 1992 & 359.10 & 14.90 & $1,400.97$ \\
\hline 9 & 1993 & 659.20 & 15.34 & $1,572.35$ \\
\hline 10 & 1994 & 500.90 & 18.20 & $1,608.98$ \\
\hline 11 & 1995 & 559.60 & 18.00 & $1,664.50$ \\
\hline 12 & 1996 & 529.30 & 17.17 & $1,579.42$ \\
\hline 13 & 1997 & 649.94 & 17.60 & $1,569.57$ \\
\hline 14 & 1998 & 393.69 & 19.73 & $1,842.76$ \\
\hline 15 & 1999 & 205.14 & 17.34 & $1,590.04$ \\
\hline 16 & 2000 & 515.03 & 16.87 & $1,584.93$ \\
\hline 17 & 2001 & 408.49 & 19.80 & $1,057.93$ \\
\hline 18 & 2002 & 544.33 & 17.54 & $1,211.78$ \\
\hline 19 & 2003 & 648.19 & 16.60 & 1,384.81 \\
\hline 20 & 2004 & 404.46 & 17.40 & $1,144.39$ \\
\hline 21 & 2005 & 417.07 & 17.43 & $1,150.81$ \\
\hline 22 & 2006 & 415.26 & 15.18 & $1,465.12$ \\
\hline 23 & 2007 & 415.88 & 13.65 & $1,820.02$ \\
\hline 24 & 2008 & 350.76 & 15.36 & $1,294.48$ \\
\hline 25 & 2009 & 484.50 & 15.55 & $2,064.96$ \\
\hline 26 & 2010 & 376.16 & 21.95 & $2,143.48$ \\
\hline 27 & 2011 & 431.55 & 19.45 & $1,931.28$ \\
\hline 28 & 2012 & 436.08 & 15.49 & $2,013.11$ \\
\hline 29 & 2013 & 489.90 & 18.18 & 2,127.95 \\
\hline 30 & 2014 & 413.17 & 17.14 & 2,098.32 \\
\hline 31 & 2015 & 389.12 & 17.78 & $2,232.74$ \\
\hline 32 & 2016 & 365.49 & 18.43 & $2,011.78$ \\
\hline
\end{tabular}

